\title{
Discussion on the New Thinking of the Creation of Domestic Animated Script
}

\author{
Zhang Xiaobo
}

Weinan Normal University, Silk Road School of Art, Weinan, Shaanxi, 714099

Keywords: Domestic Animation, Script Creation, New Thinking, Innovation

\begin{abstract}
Animation script creation is the foundation of a drama. It plays the most important role in an animated cartoon. The quality of animated cartoons and animated films depends on the creative orientation, cultural perspective and story character of script creation. But most of the students and the company's creative animation script writing a misunderstanding, the inherent mode of thinking, the old routine, single story, no personality and national characteristics in the whole industry is a common phenomenon, so we have to seek new thinking, new ways to solve these problems. As we all know, all artistic creation should keep pace with the times and adapt to the needs of the development of the times, so as to continue to flourish and keep its artistic youth and artistic charm forever. Therefore, this combination of personal for a long time thinking and practice of teaching the subject of new thinking of domestic animation script creation, put forward their own views, make the bait.
\end{abstract}

\section{Problems in the Creation of Domestic Animated Script}

The creation of animated script is the base of a play, which plays the most important role in a cartoon, and the good or bad of the script depends on the level of the screenplay. The main reason is the level and level of domestic animation writers. This article will focus on the animation company's screenwriters and animation majors.

\subsection{Animated scripts lack innovative breakthroughs}

Confucianism in China is deeply rooted and influential. The most obvious manifestation is that the most representative of children's education is accompanied animation. The child's world is simple and the things she likes are very pure. From infancy it is interested in the colorful TV screens of sports, and various animations will accompany her childhood. As a result, a large number of animated themes are biased towards preaching, innovative breakthrough, more entertainment and thinking [1]. Domestic animation is similar to the "pleasant goat and grey wolf animated full screen for many years, the children occupied remote time, the family was forced to follow the children, the plot of the story line, the infant education means is too single, too heavy, violent, dangerous behavior and the inside is full of patience, let parents see do not go.

Many animated cartoons, such as monsters, superpowers, like these episodes, are constantly creating and attracting children. Is the level of the screenwriter and the director so low? The main reason is that domestic animation writers are not valued in China. Their sense of accomplishment is low, their income level is low, and they lack professional animation writers. These are all fatal injuries to animated script.

\subsection{A work lacks a unique style.}

Audiences in different races, regions and countries enjoy different angles of animation. Even the audiences of different races and regions will have different opinions on their positions. The animation works can not reflect the style of the times and the local national style, which leads to the incompatibility of the stories and scenes, and the phenomenon of the ancient and modern blending occurs [2].

The animated film "Qin moon" is a 3D martial arts fantasy works, it is the story of the background from the Qin Shihuang out of the six countries to concubine Xiang Yu Xianyang captured during the historical period heroes, which is a martial arts themed national animation film 
type. But the playwright is too thin and thin to write the story. At least it doesn't make people see the light. When we see the beginning, we can see the ending. The main character is flawed design toward Japan style, misfits and background story.

The animated film "Kuiba" the best embodies the core spirit of the Chinese keep from talking about. What about the Chinese did not see in this animation, the story is set Chinese; characters all is a Japanese anime style, the film Kuiba took 5, finally announced that no longer shooting, because the box office fiasco, the film's story, no local ethnic style is the biggest mistake and sorrow [3].

\subsection{The choice of the genre is too single and the same}

The animated screenwriters are keen on preaching, and the simple and rough plot of a monster. While the previous students write professional animation script was written love on campus drama, science fiction, architectural animation, video creation result just passable effect; science fiction fantasy, romance, not straightforward show technology works more, show the next generation game scenes and characters more [4]. The story lacks the dramatic elements and the lack of conflict.

The audience to watch the animation film or film at the cinema or the media, the most valued or story, and many of our large animation and animation film is the energy, financial and human resources in the beautiful scene, beautiful character, cool special effects. This is a sense of misunderstanding, Chinese directors and writers have to learn how to tell a good story, making a script is the first thing. Therefore, some new ideas and new ideas should be incorporated into the creation of animated script [5].

\section{New Thinking on the Creation of Domestic Animated Script}

\subsection{Globalization}

The connotation of the new thinking of animation film script creation is first manifested in the thinking of globalization. Thinking to cover the whole world, thinking content to various fields, so from the perspective of globalization have the whole world in view of global vision, is a necessary quality of animation writers and practitioners. Art is not national boundaries, different countries, ethnic stories, legends, characters and other subjects can be our creative material.

The subject range of animated script creation is very broad. Many classic animations are based on novels, fairy tales, folk tales, fables, mythology, drama, religion and other forms of art. For example, the "Monkey King" and "monkey" here taken from Wu Chengen's novel "journey to the west"; "the lion king" drawn from Shakespeare's drama "Hamlett", "the prince of Egypt" derived from the "Bible" of the story [6-7].

So the animation industry professional writers should first from abroad "Green fairy tale", "Aesop's Fables" selected stories adapted or creation; secondly from traditional culture China selected stories adapted from the "historical records", or "up and down five thousand years" in the story to find material, create a new script for the animation performance.

The world's first animated film "Snow White" selected Danish masterpiece "Green fairy tale" Snow White and the seven dwarf story to the world animation to the creation of the world. It takes a widely spread fairy tale in a novel and unique way to make a brand-new interpretation. Only then did Snow White become popular in the world, and also made a beautiful first page for the history of animated film [8].

The animated film "Mulan" and "Kung Fu Panda", produced by the famous American animation company Disney, "brought" the traditional Chinese classic stories. But it has broken away from the traditional Chinese thinking mode and thinking connotation. It has also conquered the Chinese audience and the world audience with the American style of thinking, Disney's film making concept, and the new interpretation and interpretation of the Chinese drama stage personas.

\subsection{Localization}

When we are in the world and we look around the world, we should look down and look at the fertile land that I have raised me. This is the root of our roots. Every creator and playwright should 
compile materials from folk culture, fairy tales, folklore, fables, proverbs and idiom stories, fairy tales, realistic themes and even news events in the region. Looking at the cartoons in China, the awards that won the international awards are all derived from the nutrition in traditional Chinese culture and folklore, and then adapted into excellent feature films. Therefore, we should not always imitate and imitate the way of Disney animation in the US, but also make the animation scripts and short films of grounding gas adaptable and grounded.

The author of the Shaanxi Guanzhong Plain, the region spread "," Du Fu "CHANGJEI creation wine", "Aquilaria pishanjiumu Legends", these are the vivid material can be written in the animation script.

In the graduation art film creation, the author finds out his hometown to guide students to create a story: Henan nationality students created a "Li Erhei divorce", singing and dramatic characters with strong Henan opera features of the animated short film [9].

Clay animation short film "orchid flower" script writing is from a real thing happened in Yanan city of Shaanxi Province: a prospective student, when received a university admission notice of the tragic story of Usher is father because of inability to pay tuition and drank the pesticide Dutch act.

The regional culture resources such as fairy tales, folk literature, rural customs and so on can be used for reference and excavation, so that they can be integrated into the movie and TV language of animation. It is the source of our animated screenwriters to absorb the rich nutrition. Therefore, regional culture is the basic foundation of Chinese animation. The deconstruction and reconstruction of regional culture will promote the rise of Chinese animation and enhance the vitality of domestic animation.

\subsection{Humanize}

Animation script writing to have real feelings, emotions, genuine and sincere works is the most can move the audience. Therefore, the new thinking of animation play is made as the life and soul, the starting point and the end result of the human nature. The humanization of the new thinking in the creation of animation plays mainly in two aspects:

On the one hand, the script of the characters with personality characteristics and emotional characteristics of rich, complex, vivid and touching; on the other hand, but also pay attention to emotional communication and emotional interaction with the audience, the script character as "emotion" or "emotional bridge" [10].

For example, the 07 session of the Xi'an Academy of fine arts graduates "love" is the theme of animation on the expression of my grandmother's death was missing, the story of chastity. A scene in the grape farmyard, from the young girl to cut into the workplace, the time flies, Wushirenfei, the film's warmth to make every audience with the heroine tears.

\subsection{Science and technology}

Such as a company in Shenzhen produced a "new Peach Blossom Spring," the use of three-dimensional computer animation technology, using MAYA software to create a three-dimensional shadow of the new shape to make up for the traditional shadow of the plane, under the high-tech shell is rich mellow old wine - Chinese folklore.

Three-dimensional animation "summer" with MAYA software to create a three-dimensional beauty of the lotus pond created "should be exceptionally red Japanese lotus," the artistic conception, now using 3D software to create two-dimensional ink-style animation has also become a new trend.

The twenty-first Century is a high tech era, so the new thinking of animation script creation will take science and technology as one of the important connotations. High technology is widely used in animated films, such as virtual reality, motion expression capture technology and so on. And high technology can make the limit of thinking infinitely, as long as it is thought of the script, it can be produced. Therefore, for the new thinking of animation script creation, high technology should become the wings of new thinking of animation script creation, it can play playwright flying freely in the infinite artistic sky. 


\subsection{Innovative}

The adaptation of the animation script can be divided into: loyalty to the original adaptation, creative adaptation, subversion of adaptation of the story, drama and the story of the new series. Innovative embodiment is to be good at adaptation, good at subversion, breakthrough. On the basis of the old story boldly adapted for second creation.

For example, the short film "Three Advice" by communication university of China is a story adapted from "Reader" magazine. Adaptation of the script adds a lot of art forms, bold use of print engraving in the style of the film, the unique style of the screen, all the effects of black and white prints, simple thick lines. The film is a philosophical story and strong art style makes the film won the academy award for first prize.

The author's animated short film entitled "The Tortoise and the Hare tortoise" is an adaptation of creative thinking and bold ideas. After the rabbit lost the tortoise last time because of sleeping, the rabbit always wanted to defeat the tortoise. In this competition, the game began, the rabbits kicked out of a leg kick, I saw the turtle put away limbs, the use of the characteristics of the turtle shell, rolling down from the hillside, the blink of an eye to the end, the rabbit failed again.

To sum up, in the domestic animation script creation, as long as we integrate into the above 5 points mentioned above, we will make the quality of Chinese animated cartoons, animated films and student art videos achieve a qualitative leap.

\section{References}

[1] Krants V Z. On the History of the Creation of Domestic Hydroacoustic Communication Systems (Designer's Notes)[M]// History Of Russian Underwater Acoustics. 2014:742-772.

[2] Zhang M, Zi-Xi H U. The Sociological Methodology's Impact on the Creation of Domestic Reality Film_— Taking the film "A Touch of Sin" as an example[J]. Journal of Jilin College of the Arts, 2014.

[3] Lai W. Analysis Revelation of Successful Animation of Confucius on the domestic cartoon theme creation[C]// International Conference on Education, Management and Computing Technology. 2014.

[4] Burch J. Assessing the Viability of Creating a Domestic Intelligence Agency[J]. Dissertations \& Theses - Gradworks, 2013.

[5] Roche M. 'Creating a New Domestic Niche Market for Lamb Meat in New Zealand: Case Studies of Small Scale Experimentation'[J]. 2015.

[6] French T. The JCP and the Domestic Context of the Creation of the NPR: 1945-1950[M]// National Police Reserve. Brill, 2014:40-76.

[7] Spyra Z. The place of customer value in creating the business models of domestic private labels producers [J]. 2013:17.

[8] Shimizu A. Domestic Violence in the Digital Age: Towards the Creation of a Comprehensive Cyberstalking Statute[J]. Berkeley Journal of Gender Law \& Justice, 2013.

[9] Kinney M, Liu H. Corporate Responses to the Repatriation Incentive and Domestic Production Activities Deduction of the American Jobs Creation Act of 2004[J]. Social Science Electronic Publishing, 2016, 9(Pt 6):347-54.

[10] Perelmuter Y S. Creation of First Domestic Classification Systems for Submarine Sonar Systems[M]// History Of Russian Underwater Acoustics. 2015:545-556. 